\title{
Advanced Uterine Cervix Squamous Cell Carcinoma in 17 Year Old Adolescent -Case Report
}

\author{
Rodrigo Renee Ferreira ${ }^{1 *}$, Claudio Sergio Batista ${ }^{1}$, Cristiane Bedran Millito $^{2}$, Gabriela Coutinho Alves ${ }^{3}$ and \\ Régis Rodrigues Vieira ${ }^{4}$
}

${ }^{1}$ Department of Gynecology and obstetrics, School of Medicine of Petropolis, Brazil

${ }^{2}$ Department of Pathological Anatomy, School of Medicine of Petropolis, Brazil

${ }^{3}$ Medical student, School of Medicine of Petropolis, Brazil

${ }^{4}$ School of Medicine of Petrópolis, Brazil

Submission: January 05, 2018; Published: January 23, 2018

"Corresponding author: Rodrigo Renee Ferreira, Department of Gynecology and obstetrics, School of Medicine of Petropolis, Rua Princesa Dona Paula, 293/101-Correas, Petropolis, Rio de Janeiro, Brazil, Email: rodrigorenee@hotmail.com

\begin{abstract}
Introduction: Cervical cancer is the third most frequent tumor in the female population worldwide and fourth cause of death of women from cancer in Brazil. Natural history of cervical cancer usually presents a long period of precursor lesions, asymptomatic evolution, but is curable in most cases, if detected early.

Case: This report describes the diagnosis and management of the case of a 17 year old girl with advanced invasive squamous cell cancer of the uterine cervix. The patient presented intermittent vaginal bleeding for seven months with foul odor, accompanied by dyspareunia and intercourse bleeding. Prior to treatment with 26 sessions of radiotherapy and six sessions of chemotherapy and three sessions of brachytherapy, she was submitted to oophoropexy in the attempt to preserve the ovaries due to the patient's age and minimize the damage in fertility due to radiotherapy and brachy therapy. After an initial satisfatory response with regard to lesion decrease and bleeding improvement there was tumor relapse, when it was decided, that the patient should be submitted to total exenteration, but she died three months later. An immune histochemical study found HPV subtypes 6, 11,16 and 18.
\end{abstract}

Conclusion: This case report signalizes that, although advanced cervical cancer in very young women is rare, it should be regarded as possible and only its early diagnosis may prevent catastrophic outcomes like that.

Keywords: Uterine cervical neoplasms; Carcinogenesis; Adolescent; HPV; Radiotherapy; Adjuvant chemotherapy; Immunohistochemistry

Abbreviations: CIN: Cervix Intraepithelial Neoplasia; HPV: Human Papilloma Virus; CT: Computerized Tomography

\section{Introduction}

Cervical cancer, although largely preventable, is the most common site of gynecologic malignancy in women $<35$ years of age in the United States. Worldwide, cervical cancer is the second placed [1], behind only breast cancer among all types that affect women [2]. In Brazil cervical cancer is the third most frequent tumor in female population, behind only breast and colorectal cancer, and the fourth cause of cancer death in Brazil $[3,4]$. Cervical cancer is the third most common cancer and the fourth leading cause of cancer death in women worldwide [5]. Patient age has been posited as a risk factor for greater aggressiveness from cervical cancers. The younger they are, the more aggressive it is [6]. It seems improbable for young women to develop advanced disease, considering the classic teaching that the progression risk from mild dysplastic cervix to severe one, let alone cancer, is only $1 \%$ per year [7].

However, the cancer development in young women and especially in very young ones has led to the theory that cervical cancer must be more aggressive on them [8]. Several investigators have examined the relation between age at diagnosis and prognosis with conflicting results. In a study by Rutledge et al. [9] 250 women $<35$ years were matched by stage and treatment to older women. Younger women with advanced stage disease were noted to have a worse overall survival, yet they survived longer when diagnosed with early-stage disease. 
Human Papillomavirus (HPV) can be detected in more than $99 \%$ of cervical cancers and is essential for the malignant transformation. More than 40 subtypes of HPV have been identified, of which at least 15 are known to be oncogenic. The most common subtypes, HPV 16 and 18, account for about $70 \%$ of cervical cancers in the United States [10].

Cervical cancer is the most common of gynecological cancers in women. High-risk human papillomavirus (HPV) is implicated as the major etiologic agent. Most invasive cervical cancers are preceded by a severe cervical dysplasia or carcinoma-in-situ and common symptoms associated with cervical cancer are postcoital and irregular vaginal bleeding; watery vaginal discharge; and physical signs associated with venous, lymphatic, neural, or urethral compression. Diagnosis of cervical cancer usually follows a physical examination and histologic evaluation of cervical biopsies. Cervical cancer is staged clinically, and stage is the most important indicator of survival, and treatment is typically dictated by its clinical staging. In general, earlystage disease is treated effectively with either surgery or chemoradiation. Advanced-stage disease is treated primarily with chemoradiation [11].

This report shows an uncommon case of advanced uterine cervical cancer in a 17-year-old girl who had a poor outcome and presented the patient's death as a final outcome in a short period of time despite all spent efforts, so the attention of gynecologists is drawn, to keep in mind that uterine cervical cancer can occur even in very young women.

\section{Case Report}

B.S.C, 17 years old, single, residing in the city of Rio de Janeiro - RJ, sought medical attention at the Alcides Carneiro Teaching Hospital (ACTH), Petropolis-RJ, Brazil, with intermittent vaginal bleeding for seven months with foul odor, accompanied by dyspareunia and intercourse bleeding.

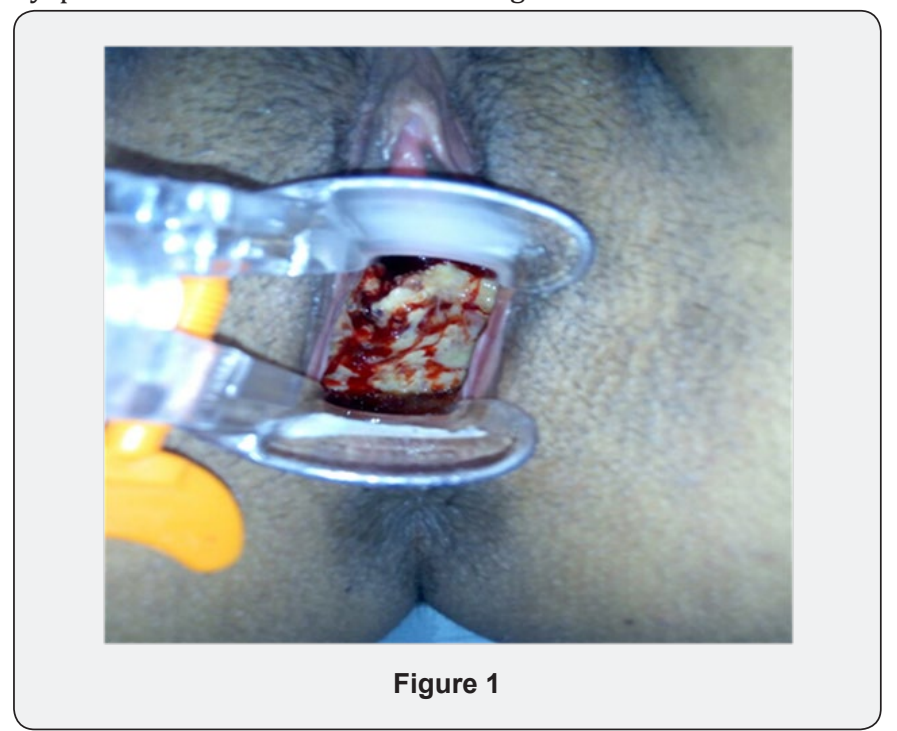

The patient reported her sexual life onset at 15 years and denied: weight loss, fever, bowel rhythm modification, hormonal contraceptive use and claims to have never had a Pap smear.
Specular vaginal examination showed liquid, blood, foul-smelling discharge, vaginal walls apparently with no lesions, and white and friable cervix exophytic lesion, with necrosis, measuring more than $4 \mathrm{~cm}$ (Figure 1) in its largest diameter and located in the superior third of the vaginal cavity. At the touch, elastic vaginal wall was noted and palpable tumor in cervix covering its entire surface, with painful mobilization, and softened consistency. At rectal touch, parametrians were free.

Cervix biopsy was performed, the piece put into a sterile vial with formalin and sent to laboratory for histopathological analysis. Immunohistochemical study for HPV research was positive to types $6,11,16$ and 18 . The patient stayed in a hospital regimen with antibiotic therapy due to secondary infection of the lesion. In this period Thoracic Computerized Tomography (CT) and abdomen and pelvic Nuclear Magnetic Resonance were performed for adequate disease investigation and its staging.

The patient was submitted to laparoscopic ovarian transposition (oofhoropexy) to take both from the radiation field, and after surgery was referred to 26 radiotherapy sessions and six of platinum-based chemotherapy ones. After ending of that treatment stage, the patient was reevaluated and presented significant lesion reduction, general appearance improvement, no visible necrosis points, and no significant vaginal discharge, with no foul odor.

Finally, patient received three brachytherapy sessions, with satisfactory response. Its follow-up was out by ACTH Oncoginecology service.

Three months after ending brachytherapy, patient evolved with tumor progression reaching the uterine body, both right and left parametrium, partial ureter obstruction and bilateral hydronephrosis, mainly to the right side. So, total pelvic exenteration with confection of Bricker neo-bladder and right colostomy was performed externally and the patient was sent for outpatient follow-up.

Unfortunatelly, patient had bad evolution and died 3 months after exenteration procedure at 26 November 2017. Case presentation had as patient's autorization as her responsible, and was submitted and approved by the Ethics Committee of the Faculty of Medicine of Petropolis, RJ, Brazil.

\section{Discussion}

The purpose of this work is to draw attention to cases of uterine cervical cancer in very young women who, although rare, are more aggressive than in older women. Even though guidelines for cervical cancer screening recommend starting from 25 years, we understand this case report indicates caution in this pratice. Several investigators have examined the relation between age at diagnosis and prognosis with conflicting results [12]. However trends in incidence of cervical cancer in younger women have not been studied in detail, yet [13]. 
Thus, it is known that cervical cancer in young and very young women tends be complex, and a risk factor for greater aggressivity, but that data should be better collected and characterized.

Currently, cervical cancer control is priority in the Brazil's Health Program and is part of the Strategic Action Plan for Coping with Chronic Nonco.3 Risk factors for cervical cancer are early sexual activity (16 years or less), multiple partners, HPV infection, sexually transmitted diseases (STDs) and Cervix Intraepithelial Neoplasia (CIN). Smoking and Acquired Immunodeficiency Syndrome (AIDS) are additional factors. In contrast with literature data, the patient denied any known uterine cervix cancer risk factors except early sexual onset at 15 years.

Uterine cervix squamous cell carcinoma appears at the squamocolumnar junction as dysplastic lesion, generally, following HPV infection [14], and despite different agents having been suggested as participants in cervical cancer genesis, HPV is the most important of them appearing in $90 \%$ of cases, and subtypes $16,18,31,33$ and 35 are found in about $70 \%$ of cases. Subtypes 16 and 18 are the most studied due to their high frequency in cervical cancer.

Parametrial invasion and extension for the lateral pelvic wall may compress adjacent organs and produce symptoms such as lower limb edema and lower back pain while urethral obstruction produces hydronephrosis and uremia. Tumor invasion into bladder and rectum may cause vesicovaginal and rectovaginal fistula [15].

In order to establish the size of the primary tumor and to diagnose its eventual extension, contiguous organs and structures must be rigorously analyzed. Rectal examination should be performed accurately since parametric conditions and disease stage depends on this record.

Cervical cancer stages classifications were defined by the International Federation of Gynecoloy and Obstetrics (IFGO) in 1996, by the American Joint Committee on Cancer (AJCC) in 2002, and by Tumor, Lymph node and Metastasis (TNM) system in 1995, being IFGO's the most used one among them.

This case report is about cervix cancer stage IB2 IFGO, in which recommended treatment options are: chemoradiotherapy; radical hysterectomy and bilateral pelvic lymphadenectomy, often followed by adjuvant radiotherapy; neoadjuvant chemotherapy (3 cycles of platinum) followed by radical hysterectomy with bilateral pelvic lymphadenectomy, often followed by radiotherapy or adjuvant chemoradiotherapy.

The suggested dose of radiotherapy is 85 to 90 Gy at point A and 55 to $60 \mathrm{~Gy}$ at point B. Platinum is prescribed at a dose of 40 $\mathrm{mg} / \mathrm{m}^{2}$ once weekly during external radiation therapy. Radical hysterectomy for IB2 tumor stage is selected for premenopausal women who wish to preserve ovarian function and for those who are concerned with changes in sexual function after radiotherapy.
In those who opt for surgery, abdominal radical hysterectomy is usually performed, body and cervix, parametrium and paracolpus, uterine vessel ligation, transection of uterosacral ligament, excision of $2 \mathrm{~cm}$ of vaginal upper third being removed $[16,17]$.

Neoadjuvant chemotherapy with platinum, followed by radical hysterectomy has demonstrated better results than primary radiotherapy. On the other hand, there is no avaliable information comparing the results of chemoradiotherapy with neoadjuvant chemotherapy followed by surgery $[18,19]$.

The most common treatment option was adopted for this stage that is radiotherapy plus simultaneous platinumbased chemotherapy, weekly, followed by brachytherapy. This treatment is Level of Evidence A [20].

This case report signalizes, although advanced cervical cancer in very young women is rare it should be considered possible and only its early diagnosis may prevent catastrofic outcomes like that.

\section{Acknowledgement}

Authors are thankfull to Dr. Thiago Kloh and Dr. Guilherme Guedon, Titular of Oncology Surgery, Dr César Luiz da Silva Gomes, Titular of Anesthesiologya and Dr Marcelo Frattani, Resident Doctor of Programme of Anesthesiology for their participations and tech support to the patient's exenteration and her post-operative period.

\section{References}

1. Zur Hausen H (1999) Viruses in human cancers. Eur J Cancer 35: 11741181.

2. Boyle B, Levin B (2008) World Cancer Report 2008. International Agency for Research on Cancer, Lyon, France.

3. (2016) Diretrizes brasileiras para o rastreamento do cancer do colo do utero, Instituto Nacional de Câncer Jose Alencar Gomes da Silva, Coordenação de Prevenção e Vigilância. Divisão de Detecção Precoce e Apoio a Organização de Rede, ( $2^{\text {nd }}$ edn), Atual, Rio de Janeiro, INCA.

4. Ferlay J, Shin HR, Bray F, Forman D, Mathers C, et al. (2011) Cancer incidence and mortality worldwide. IARC Cancer Base No. 10 [Internet]. Lyon, France.

5. Jemal A, Bray F, Center MM, Ferlay J, Ward E, et al. (2011) Global cancer statistics. CA Cancer J Clin 61(2): 69-90.

6. Hemminki K, Chen B (2016) Familial risks for cervica ltumors in full and half siblings: etiologic apportioning. Cancer Epidemiol Biomarkers Prev 15(7): 1413-1414.

7. Holowaty P, Miller A, Rohan T, To T (1999) Natural history of dysplasia of the uterine cervix. J Natl Cancer Inst 91(3): 252-258.

8. Hildesheim A, Hadjimachael O, Schwartz P, Wheeler CM, Barnes W, et al. (1999) Risk factors for rapid-onset cervical cancer. Am J Obstet Gynecol 180(3 Pt 1): 571-577. 
9. Rutledge F, Mitchell MF, Munsell M, Bass S, McGuffee V, et al. (1992) Youthasa prognostic fator in carcinoma of the cervix: amatched analysis. Gynecol Oncol 44(2): 123-130

10. Committee on Practice Bulletins-Gynecology (2002) ACOG practice bulletin. Diagnosis and treatment of cervical carcinomas, number 35, May 2002. Obstet Gynecol 99(5 Pt 1): 855-867.

11. Jayanthi SL, Ken YL (2012) Cervical cancer. Obstet Gynecol Clin N Am 39(2): 233-253.

12. Pelkofski E, Stine J, Wages NA, Gehrig PA, Kim KH, et al. (2016) Cervical Cancer in Women Aged 35 Years and Younger. Clinical Therapeutics 38(3): 449-466.

13. Foley G, Alston R, Geraci M, Brabin L, Kitchener H, et al. (2011) Increasing Rates of Cervical Cancer in Young Women in England: An Analysis of National Data 1982-2006. Br J Cancer 105(1): 177-184.

14. Bosch FX, Munoz N (2002) The viral etiology of cervical cancer. Virus Res 89(2): 183-190.

15. Hoffman (2014) Ginecologia de Williams. (2 ${ }^{\text {nd }}$ edn), AMGH, Porto, Alegre.

16. FMUSP (2016) Condutas em ginecologia baseadas em evidências.

17. (2014) Manual de Condutas em Ginecologia Oncológica. AC Camargo Cancer Center, Departamento de Ginecologia, (2 $2^{\text {nd }}$ edn), São Paulo, Brazil.

18. Rose PG, Adler LP, Rodriguez M, Faulhaber PF, Abdul-Karim FW, et al. (1999) Positron emission tomography for evaluating para-aortic nodal metastasis in locally advanced cervical cancer before surgical staging: a surgicopathologic study. J Clinic Oncol 17(1): 41-45.

19. Stewart LA, Tierney JF (2002) Neoadjuvant chemotherapy and surgery versus standart radiotherapy for locally advanced cervix câncer. A metaanalysis using individual patient data from randomized controlled trials. Int J Gynecol Cancer 12: 579.

20. Peters WA, Liu P, Barrett RJ, Stock RJ, Monk BJ, et al. (2000) Concurrent chemotherapy and pelvic radiation therapy compared with pelvic radiation therapy alone adjuvante therapy after surgery in high risk early-stage câncer of the cervix. J Clinic Oncol 18(8): 1606-1613. 
Your next submission with Juniper Publishers will reach you the below assets

- Quality Editorial service

- Swift Peer Review

- Reprints availability

- E-prints Service

- Manuscript Podcast for convenient understanding

- Global attainment for your research

- Manuscript accessibility in different formats

( Pdf, E-pub, Full Text, Audio)

- Unceasing customer service

Track the below URL for one-step submission https://juniperpublishers.com/online-submission.php 